\title{
Use of Digital Elevation Models to Map Out The Groundwater Resources Base Of Kuje Area to f Federal Capital Territory, Abuja, Nigeria
}

\section{*MEPHORS, JO; OGUNMUYIWA, CO; AFOLABI, OS; AGBOR, CF; OGOLIEGBUNE, OM; OFORDU, CS}

\author{
Environmental Modelling and Biometrics Department,Forestry Research Institute of Nigeria, P.M.B. 5054 Jericho Hills, \\ Ibadan, Oyo State, Nigeria \\ *Corresponding Author Email: justinaalagbe@gmail.com
}

\begin{abstract}
This research work examined the use of digital elevation model in the evaluation of groundwater resources in Kuje Area, Nigeria. This was achieved through the acquisition of topographic maps, Digitization of the topographic maps which were glued and interpolated to generate Digital Elevation Models (DEM) and Mapping of groundwater potential areas using ArcGIS 9.2 and ArcView 3.2a software. Findings from this research show that the study area have elevations ranging from $333 \mathrm{~m}$ to $429 \mathrm{~m}$ above sea level with a moderate groundwater potential in areas with elevation ranging from $286 \mathrm{~m}$ and $333 \mathrm{~m}$ above sea level. Some areas also have ground water problem, these areas were classified as mountainous areas and are located at very high elevations. The rocky nature of the high elevated environment makes these areas have very little hope of assessing groundwater. It was suggested that government should properly monitor groundwater, inhabitants should be made to accept laws which will help them in the conservation of ground water resources and efforts should also be made by the government towards creating incentives that will encourage people to obey these laws, Conservation methods such as retardation of surface runoff, control of vegetation and groundwater withdrawal rates should be employed.
\end{abstract}

\section{DOI: https://dx.doi.org/10.4314/jasem.v25i7.16}

Copyright: Copyright $\odot 2021$ Mephors $e t$ al. This is an open access article distributed under the Creative Commons Attribution License (CCL), which permits unrestricted use, distribution, and reproduction in any medium, provided the original work is properly cited.

Dates: Received: 10 May 2021; Revised: 28 June 2021; Accepted: 01 July 2021

Keywords: Groundwater, Digital Elevation Model, Topographic maps, Geo-spatial techniques

The amount and flow of groundwater is measured by geological factors. The crystalline basement rocks only have secondary permeability arising from joints, fissures/fractures and intergranular porosity (Olayinka, 1992; Amadi and Olasehinde, 2010; Ojo et al., 2015). Groundwater potential is one of the most difficult fields for estimation, as it is unmanageable to conduct direct measurements in all areas; the groundwater potential is the potential of an area to be an aquifer that could be used for groundwater development (Sunmin et al., 2019). The circulation of groundwater recharge and discharge areas in the landscape can be described simply as recharge areas at local heights and discharge areas at local depressions. The area in between the two can be a discharge area during wet periods and recharge area during dry periods. This easy report depends on topography; however, advanced geo-hydrological models use much more factors such as soil distribution in three dimensions, vegetation, land use, and bedrock fracture zones (Lars, 2006). With regards to water management, water security is essential to actively deal with environmental threats due to economic changes or natural disasters (Vörösmarty et al., 2010). In particular, changes in environmental conditions such as increased drought due to climate change, industrialization, urbanization, nuclear power plant accidents, and other disasters have underscored the importance of ensuring sustainable and high-quality water resources. Groundwater resources with high levels of safety against environmental threats are considered a key future resource (Oki and Kanae, 2006). In semi-arid environments, most land use depends on water harvested from the upper part of soil to support crops on the lower members (Mokarram et al., 2018). The entire process of water movement depends largely on the elevation of the area (derived terrain parameters), which goes into the process of characterizing the landforms (Haldar et al., 2011). The reliability of water resources management is influenced by predictability of hydrological cycle. Indeed land use, topography, soil and geology characteristic, and artificial water use (mainly agricultural irrigation) are several factor affecting the complexity of hydrological cycle in the basin. Understanding the hydrological mechanism in the basin has been a main concern in development of hydrological modeling, aiming to establish sustainable of land use and water use (Hendra et al., 2013). Satellite based remote sensing data are proficient in 
revealing structural features including faults, fractures and different landforms. The effectiveness of remote sensing as a rapid assessment tool in groundwater investigation has been emphasized by the following scholars (Singh et al., 2013; Ndatuwong and Yadav, 2014; Badamasi et al., 2016) their joined approach is particularly fascinating as it is applicable even in inaccessible areas. In recent years, spatial data collected from remote sensing platforms have accumulated in various fields, and the use of large spatial datasets has spread widely. As data is created and managed in a variety of ways, it becomes increasingly important to analyze the complexity of the data and to understand the relationships within the data (Sunmin et al., 2019). The objective of this paper employ Digital Elevation Models to map out the groundwater resources base of Kuje Area of Federal Capital Territory, Abuja, Nigeria with a view to determine their importance as well as monitor them for proper use and management.

\section{MATERIAL AND METHODS}

Study Area: The study area is located between latitude $8^{\circ} 53^{\prime} 47^{\prime \prime} \mathrm{N}$ and longitude $7^{\circ} 14^{\prime} 24^{\prime \prime} \mathrm{E}$ north and east of Abuja and south of Abaji area councils (Jimme et al., 2015) as shown below in (Fig. 1). The study area is about $40 \mathrm{~km}$ south west of Abuja, the Capital of Nigeria. Kuje has a total land mass of 1,800sqkrn about (22.5\% of FCT) and a population of 97,367 at the 2006 census, due to urban population growth rate of $4.52 \%$ (Jimme et al., 2015). It comprises of two major districts, Kuje central and Rubochi. The area comprises of different ethnic groups with varying cultural and social backgrounds namely the Egbirakoto, Gade, Gbari, Gbagyi, Bassa, Hausa-fulani and others. The people are predominantly farmers and traders who specialize in agriculture and livestock breeding. However, other economic activities of the people includes trading in pharmaceuticals, provisions, building materials and other essentials such as fruit, vegetables, fresh meat, household goods, fabric, shoes, clothing and smoked fish (Jimme et al., 2015).

Data Collection: Data collected for the purpose of this research work which include data acquired and source, map properties, software's used, Topographical maps covering Kuje Area Council with sheet numbers 207 $\mathrm{NW} / 4 \mathrm{C}$ and $207 \mathrm{NW} / 2 \mathrm{~F}$ at scales of 1:10,000 which were obtained from Federal Capital Development Authority (FCDA) are the secondary data used in this research work.



Fig 1: Administrative map of Kuje Area Council

Table 1: Tabular representation of data acquired and its sources

\begin{tabular}{lllll}
\hline S/N & DATA TYPES & SHEET NUMBER & SCALE & SOURCE \\
1. & Administrative Map of Kuje & - & - & GIS Lab Uniabuja \\
2. & Topographical Map & $207 \mathrm{NW} / 4 \mathrm{C}$ & $1: 10,000$ & FCDA \\
3. & Topographical Map & $207 \mathrm{NW} / 2 \mathrm{~F}$ & $1: 10,000$ & FCDA \\
\hline
\end{tabular}


Data analysis: Basically, three software's were used for this project. They include;

a) ArcGIS 9.2: This was used for the georeferencing as well as the digitizing of the maps

b) ArcView 3.2a: This was used in the generation of the Digital Elevation Model (DEM).

c) Microsoft Word 2007: It was used for the presentation of the research work.

\section{Image processing}

1. Scanning of The Maps: The maps were scanned and saved as TIF files so that digital processing could be carried out.

2. Geo-Referencing: The maps were geographically referenced, this is to allow it have corresponding co-ordinates on paper with the coordinates on ground. This was achieved using ArcGIS 9.2.

3. Digitization: The contour lines, rivers and spot heights were digitized using ArcGIS9.2

4. Production of Drainage Maps: This was done using ArcGIS 9.

5. Generating Dem: Generation DEM to allow a three dimensional visualization of the maps for proper interpretation and other analysis was carried out using ArcView 3.2a.

6. Conversion to Microsoft word Printable Format: The finished/ embellished work was converted to a Microsoft word printable format by exporting it and saving it as a JPEG file from ArcView 3.2a interface.

7. Printing: The Digital Elevation Model as well as other literatures for this research work was printed using HP Desktop printer (5600 series).

\section{RESULTS AND DISCUSSION}

Digital Elevation Model of Sheet 207 NW/2F: As earlier explained digital elevation model (DEM) is an image or data array representing the spatial distribution of elevation above some arbitrary datum in the landscape. DEM describes the altitude or height above datum or an arbitrary unit which can be contoured using magnetic gravimetric data etc. DEM 1 shown in figure 3 below, which was generated from sheet $207 \mathrm{NW} / 2 \mathrm{~F}$ clearly shows that the lowest elevation is found around River Usuma with elevations ranging from $218 \mathrm{~m}$ above sea level to $272 \mathrm{~m}$ above sea level. The elevation of the area increases gradually towards the eastern part with the highest elevation at $345 \mathrm{~m}$ above sea level. The elevation of the areas on DEM 1 translates to the groundwater potential as the areas with low elevation are areas with high groundwater potential while areas of high elevation have lesser groundwater potential. Areas classified as having high groundwater potential includes areas with elevation ranging from $218 \mathrm{~m}$ to $272 \mathrm{~m}$ above sea level. They are well drained by River Usuma and its tributaries as such a community like Lafia found around co-ordinates North 986500 and East 304300 will benefit a lot without the involvement of advanced technology when it comes to the utilization of the groundwater in the area. In another vein, areas considered as having medium groundwater potential are found in the central region of the DEM. This is because elevations though not relatively low; it cannot be classified as high.



Fig 3: (DEM 1) Digital Elevation Model derived from sheet 207 NW /2F Abuja.

$H=H i g h$ ground water resources potential, $M=$ Medium, $L=L o w$ groundwater Potential.

These areas although well drained by the tributaries of River Usuma, the water level is not as high because of the distance from major river channel in the basin as well as other factors such as low level of drain water concentration. These areas have elevation ranging from $272 \mathrm{~m}$ above sea level to $290 \mathrm{~m}$ above sea level. Areas considered as having low groundwater potential include areas with elevations ranging from $290 \mathrm{~m}$ to $327 \mathrm{~m}$ above sea level. The high elevation is a problem when it comes to the utilization of the groundwater. Advanced technology will be needed to utilize the water in these areas and proper care has to be taken to avoid the wasteful use of the resources in this area. 
Digital Elevation Model of Sheet 207NW/4C: DEM 2 which was generated from sheet 207 NW/4C shows that the area is almost evenly drained by the tributaries of River Usuma which can be found on DEM 1, as such, the groundwater potential of the area is moderate. The fact is that the elevation of the area is moderately high compared with elevations on DEM 1. This DEM has its lowest elevations ranging from between $238 \mathrm{~m}$ above sea level to $286 \mathrm{~m}$ above sea level which could be considered as high when compared with DEM 1 whose lowest elevations ranges from between $218 \mathrm{~m}$ above sea level to $272 \mathrm{~m}$ above sea level. From DEM 2, areas classified as medium have lots of surface water potentials in the form of rivers and streams during the raining season because of the elevation of the area which is neither high nor low covering a wide area. Elevation in these area ranges from between $238 \mathrm{~m}$ above sea level to $286 \mathrm{~m}$ above sea level, thus groundwater generation will be relatively easy. There is high concentration of young streams and rivers in the south-eastern part of the area which flow in towards River Usuma. In this study, areas classified as having moderate groundwater potential have almost even distribution of streams and rivers with very moderate elevations ranging from 238 $\mathrm{m}$ above sea level to $286 \mathrm{~m}$ above sea level. This means that the ground water is located close to the surface as such to extract the water, wells and boreholes will not need to be dug very deep this will also safe time, and money and little manpower as well as technology will be required. Areas of high elevation were classified as having low groundwater potential with elevations ranging from between $286 \mathrm{~m}$ above sea level to $333 \mathrm{~m}$ above sea level. With the high elevation therefore, it means that people will have to either travel long distance to get water or more sophisticated technology will be needed if the little and distanced groundwater in the area is to be utilized (DEM 2). Areas classified as mountainous are areas located at very high elevations. They have elevations ranging from $333 \mathrm{~m}$ above sea level to $429 \mathrm{~m}$ above sea level. These areas are located so high and in rocky environment that they have very little hope of accessing groundwater. To get groundwater in these areas, advanced technology will be required which will cost a lot of money, people will also have to travel long distance to get water.

Digital Elevation Model of Kuje Area Council: DEM 3 was generated as a result of the gluing of DEM 1 and DEM 2 (sheets $207 \mathrm{NW} / 2 \mathrm{~F}$ and 207NW/4C) and submerging only areas of concern for this study. It shows that the area is drained by River Usuma and its tributaries. The proximity of a settlement to the major river as well as its elevation therefore determines its groundwater potential. Kuje area council which is located at North 981396 and East 30500 with elevations of between $286 \mathrm{~m}$ above sea level and 333 $\mathrm{m}$ above sea level has a moderate groundwater potential.

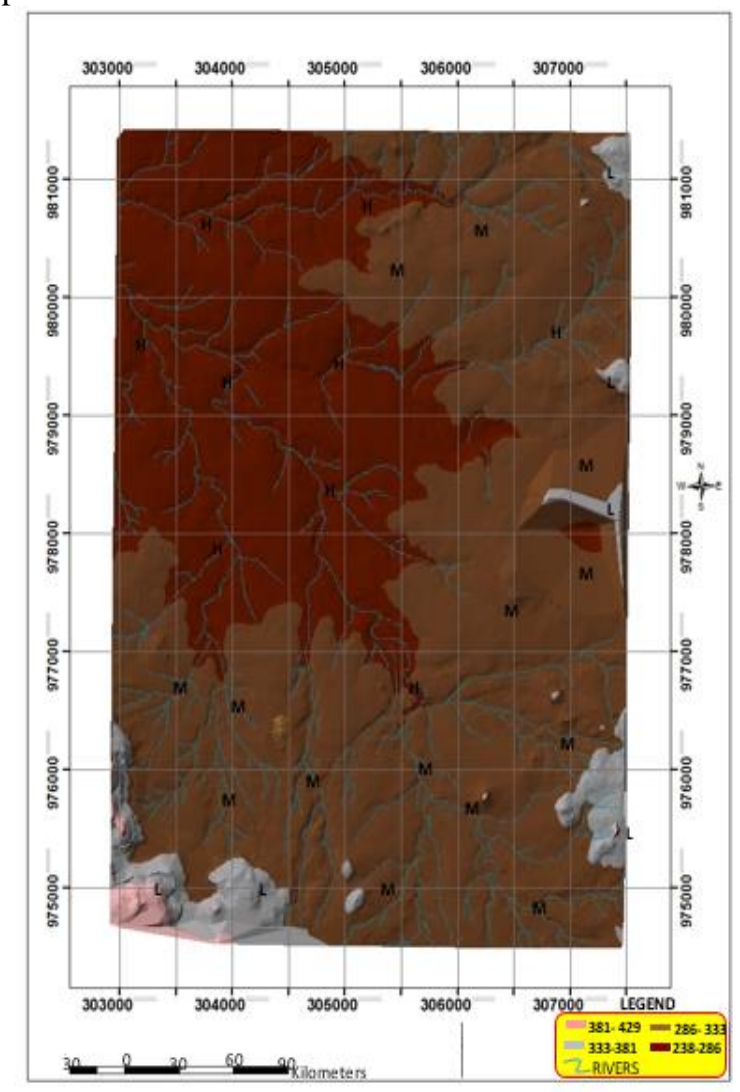

Fig 4: (DEM 2) Digital Elevation Model derived from sheet 207 NW/ 4C, Kuje.

$\mathrm{H}=$ Moderate ground water potential, $\mathrm{M}=$ Less groundwater potential, $\mathrm{L}=$ Mountainous areas

This is because though it is located quite far from the major river (Usuma); its elevation is not so high that groundwater cannot be easily accessed in the area. Boreholes will not have to be dug too deeply before groundwater can be utilized and people will not have to travel a long distance to get access to the streams which are the tributaries of the major River ( Usuma) though these streams are seasonal in nature. DEM 3 shows that the rivers and streams flow in a west-east direction from areas of moderate elevation to areas of high elevation. Areas classified as having moderate groundwater potential fall within an elevation range of between $238 \mathrm{~m}$ above sea level to $286 \mathrm{~m}$ above sea level, this is because these areas are in close proximity with the river channels (they are located close to the valleys of the rivers) and there distance above sea level is moderate as such dwellers of settlements located close to the rivers and streams such as Lafia and Kango have lesser ground depth distance get groundwater unlike Jeida and Pasati which are located 
in areas of medium groundwater potential. Jeida and Pasati have elevation ranging from $286 \mathrm{~m}$ above sea level to $333 \mathrm{~m}$ (low groundwater potential). Though the area is well drained, their distance above sea level (between $286 \mathrm{~m}$ above sea level and $333 \mathrm{~m}$ above sea level) makes it a little difficult to get or utilize the groundwater this is because their aquifer (water bearing rock) is located deeper in the ground than those of the areas with high groundwater potential. The more the distance of a settlement from the main river and the more the distance the settlements are from the underground aquifers the more difficult it becomes to get access to underground water. This is because the speed at which the river moves is high reducing the retention capacity and percolation of water along the way which has thus affected the overall volume of the underground water. Mountainous areas with no groundwater potential were classified based on their elevation which ranges from $333 \mathrm{~m}$ above sea level to $429 \mathrm{~m}$ above sea level. These areas will have their aquifer located far below the ground as such; lots of money will be spent to bring the water to the surface and sometimes, people will have to travel long distance before they can get water.

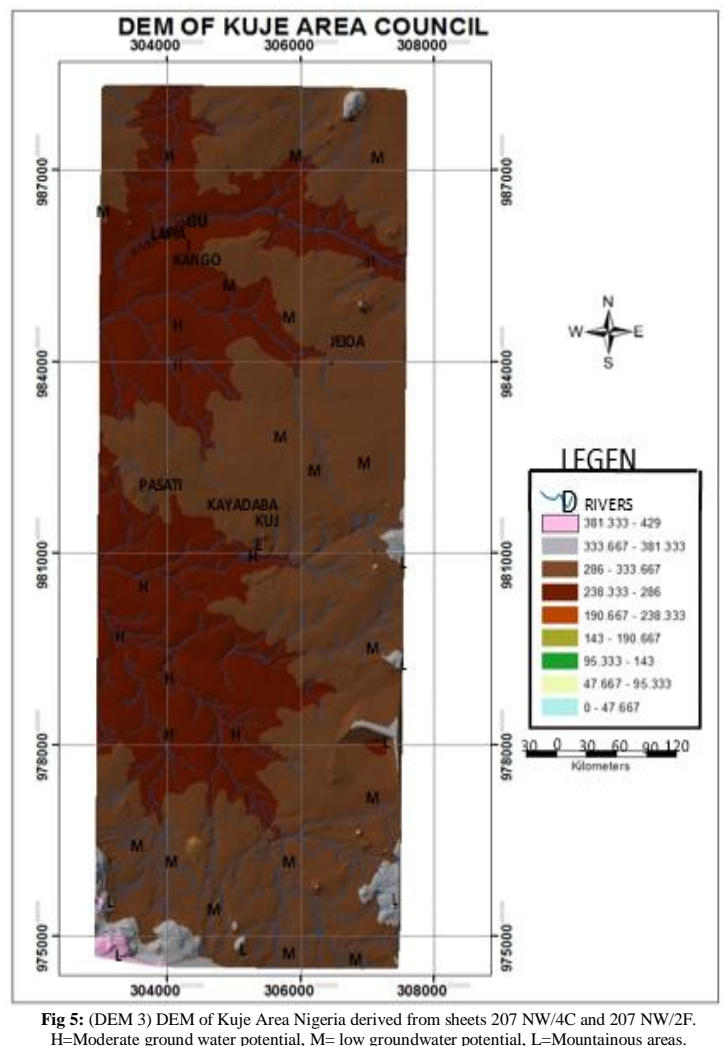

Conclusion: In conclusion this research work demonstrates the ability of GIS to be used in environmental resources (water) management. Kuje Area, Nigeria which is located at North 981396 and
East 30500 with elevations of between $286 \mathrm{~m}$ above sea level and $333 \mathrm{~m}$ above sea level has a moderate groundwater potential. This is because though it is located quite far from the major river (Usuma); its elevation is not so high that groundwater cannot be easily accessed in the area. It is recommended that methods of conservation such as retardation of surface runoff, control of vegetation and control of withdrawal rates are ways through which groundwater can be conserved. Conservation will ensure that water will be available for a very long time while it is still being used maximally.

\section{REFERENCES}

Amadi, AN; Olasehinde, PI (2010). Application of remote sensing techniques in hydrogeological mapping of parts of Bosso Area, Minna, NorthCentral Nigeria. Int. J. Phys. Sci., 5(9): 14651474.

Badamasi, S; Sawa, BA; Garba, ML (2016). Groundwater potential zones mapping using remote sensing and geographic information system techniques (GIS) in Zaria, Kaduna State, Nigeria. Am. Sci. res. j. eng., technol., sci. (ASRJETS), 24(1): 51-62.

Haldar, D; Sehgal, VK; Gopal, K; Sundara Sarma, KS (2011). Characterization of landform of Alwar District of Rajasthan (India) by deriving and using terrain parameters from DEM. AJG, 11(1): 1-14.

Hendra, P; Yasuhiro, M; Hiro, I; Ibrahim, D; Atsushi M (2013). Development of Water Management Modeling by Using GIS in Chirchik River Basin, Uzbekistan. Procedia Earth Planet, 6(2013): 169 -176 .

Jimme, MA; Gwamna, AI; Ikusemoran, M (2015). Landuse and Landcover Change Detection in Kuje Area Council of the Federal Capital Territory (FCT), Abuja, Nigeria. j. environ. sci., toxicol. food technol. (IOSR-JESTFT), 9(10): 111 .

Lars Brydsten (2006): Modelling groundwater discharge areas using only digital elevation models as input data. 38(17), pp. 1-18.

Mokarram, M; Shaygan, M; Sathyamoorthy, D (2018). Using DEM and GIS for evaluation of groundwater resources in relation to landforms in the Maharlou-Bakhtegan watershed, Fars province, Iran. J. Water Land Dev, 37(IV-VI): 121-126. 
Ndatuwong, G; Yadav, GS (2014). Integration of hydrogeological factors for identification of groundwater potential zones using remote sensing and GIS techniques. J.geosci. geomat. 2(1): 1116.

Ojo, JS; Olorunfemi, MO; Akintorinwa, OJ; Bayode, S; Omosuyi, GO; Akinluyi, FO (2015). GIS integrated geomorphological, geological and geoelectrical assessment of the groundwater potential of Akure Metropolis, southwest Nigeria. J. Geotech., 5(14): 85-101.

Oki, T; Kanae, SJ (2006). Global hydrological cycles and world water resources. Science, 313(5790): 1068-1072.
Olayinka, AI (1992). Geophysical siting of boreholes in crystalline basement areas of Africa. J. African Earth Sci., 14(2): 197-207.

Singh, P; Thakur, JK; Kumar, S (2013). Delineating groundwater potential zones in a hard-rock terrain using geospatial tools. Hydrol Sci J, 58(1): 213223.

Sunmin, L; Yunjung, H; Moung-Jin, L (2019). Groundwater Potential Mapping Using Data Mining Models of Big Data Analysis in Goyangsi, South Korea. Sustainability, 11(6): 1-21.

Vörösmarty, CJ; McIntyre, PB; Gessner, MO; Dudgeon, D; Prusevich, A; Green, P; Glidden, S; Bunn, SE; Sullivan, CA; Liermann, CR (2010). Global threats to human water security and river biodiversity. Nature, 467(7321): 555-561. 